\title{
Fiji TV's struggle \\ for good service
}

Fiji TV has behaved in the fashion of most commercial broadcasters: it has sought popular programming, and it has built a respected independent news bulletin. But politicians want news that is Government public relations and "worthy" programming.

\section{By PETER WILSON}

\section{What is "quality" broadcasting?}

TELEVISION critics frequently interpret "quality broadcasting" as a highculture concept, equivalent to serious literature and the traditional performing arts. High culture advocates frequently lament the purported lack of "quality" in commercial TV, a popular-culture medium. They assume that television should be serious, self-improving and intellectually satisfying to the highculture élite. They consider that television programming which fails to meet these criteria is dross, a waste of time, a new opiate to the masses.

Perceptions of quality can also be culturally specific. From my experience the older generation of anglophile New Zealanders, and many British expatriates, have a steadfast "British good, American bad" view of television quality.

Governments and bureaucrats in developing nations frequently hold another view of quality. The process of justifying the introduction of television in developing nations has often involved portraying television as a key factor in national development and the education of the people. Television thus becomes burdened with the expectation of transforming subsistence farmers into software engineers, or rejuvenating a traditional culture under pressure from social change. Entertainment programmes are thus considered a frivolous lapse in quality and a failure to achieve the lofty social objectives of television.

Yet the commercial model is becoming increasingly dominant in television broadcasting due to deregulation and taxation-resistance in developed coun- 


\section{PETER WILSON}

tries, or due to severe fiscal constraints in developing countries.

This is not to say that commercial television is superior to public broadcasting. Public service television is an effective means of providing a broad diversity of quality programming, provided that it is adequately funded and is independent of political control. However, in many developing countries public service television is simply not affordable, or Governments find it impossible to resist the temptation to exercise political control over the publicly owned broadcaster.

The commercial model is democratic. It is driven by advertising revenue, which is in turn driven by audience ratings, which reflect the popularity of the programmes with the audience. It cares not a fig for "quality", unless the audience itself also shares that perception of quality and has enthusiasm for it.

Does this mean the end of quality television broadcasting? I believe not. I respect the television audience and detest élitist references to "lowest common denominator". The audience is diverse. They are individuals with varying tastes and interests, including an ongoing need for quality programming.

It should be remembered that English is a second or third language to most of the Fiji audience. The Fiji 1 audience loves to relax in the evening with Shortland Street, a New Zealand prime-time soap with Pacific Island characters and even an occasional Fiji sub-plot. They enjoy the fantasy adventure of Hercules and the creepy thrills of $X$ Files. But they are also avid news watchers, keeping Fijil News and BBC World at the top of the ratings. They like international current affairs such as 60 Minutes, and are interested in Quantum, a popular science programme. They are interested in locally produced chat and magazine shows. They want programming in their native language. They enjoy local documentaries, and a significant minority watch international documentaries. And they adore sport, particularly rugby.

To Fiji TV, quality television means catering to this diversity of viewing interest with appropriate programming for each sector of our audience, while maintaining a balanced schedule. A well-structured commercial schedule can provide the right mix of local content, respected and authoritative news bulletins, popular entertainment programmes and accessible information programmes.

Undoubtedly this will never satisfy the high culture critics, and the bureaucrats whose view of the world is fundamentally at variance with commercial television. It may however go a fair way to satisfying the audience, and our own professional standards.

42 PACIFIC JOURNALISM REVIEW 5:1 1999 


\section{Achieving commercially funded quality broadcasting}

It helps to be a monopolist. This is undoubtedly heresy to the free market ideologues, whose philosophy appears to have totally conquered all public policy debate worldwide. However, the much maligned television monopolist brings some benefits to quality programming in small developing countries.

Fiji TV is the only television broadcaster in Fiji. Fiji TV is a publicly listed company, although many of our institutional shareholders trace their ultimate ownership back to public bodies. Fiji TV is a totally commercial operation, with no government funding for television operations. Fiji is a country of over 300 islands with a population of under 800,000 people. Over half of the population are subsistence farmers or fishers. The major islands are ruggedly hilly, and heavily vegetated. Transmission over mountain, sea and rainforest is expensive, yet Fiji 1, our predominantly English language national free-to-air channel, covers about 80 per cent of the population. We also operate a two-channel VHF subscription TV service, SKY FIJI.

It is unlikely that this tiny market can support more than one commercial operator. In our view, any competitive battle would quickly result in only one survivor, and would achieve little except a temporary escalation in programme costs due to competitive bidding.

As a monopoly purchaser, Fiji TV has some limited market power offsetting, to some extent, the enormous power of the international programme suppliers. This means that Fiji TV is able to acquire quality programming at a price that the Fiji market can afford. It took some years to achieve this, mainly by being patient, not purchasing over-priced product, and educating distributors about Fiji's real ability to pay. Eventually most distributors decided that a modest sale is better than no sale, and Fiji TV has been able to acquire a range of quality programming at a price that this market can bear. Competitive bidding would have shifted all market power to the international distributors, and television operators in Fiji would have paid significantly more for less.

Without the intense commercial pressure of competitive programming, Fiji TV has also been able to build diversity into its Fiji 1 schedule. In a highly competitive commercial environment, where every rating point means the difference between financial success and failure, there is a tendency to go for the safe, the predictably popular, the ratings winner in all slots. Minority interests frequently miss out. Any commercial television operator is predominantly driven to achieve attractive ratings to be "sold" to advertisers. Fiji 1 is no exception and makes no apology for this. However, monopoly gives some 


\section{PETER WILSON}

additional freedom to sustain a broadly based schedule which also caters to minority tastes and allows us to programme shows of limited appeal but high quality. This less commercial programming tends to be placed in late peak or off-peak, for we must first earn our keep in commercial prime time, but noncommercial programming is there in the schedule.

\section{Growing advertising revenue}

Monopolist or not, a commercial television operator will not survive, let alone schedule quality programming, unless they generate attractive ratings and sell advertising slots. Fiji 1 has what we believe to be the right programme mix for our market to achieve our commercial and non-commercial objectives.

As importantly, we have credible, independent audience research tracking our performance. Our most popular programme, Fiji 1 News regularly achieves ratings of over 50 per cent of the available audience. Popular prime time entertainment programmes frequently achieve ratings in the $40 \mathrm{~s}$. This quantitative research has been crucial in convincing advertisers of the cost-effectiveness of television, and has resulted in significant increases in market share against other media.

Pricing strategy is also important. We try to price television as the premium medium on a cost per spot basis, but are able to argue its cost effectiveness against other media on a cost per thousand basis. We also offer surplus inventory at a very low cost once clients have committed to a particular level of full price spend, (usually more than last year).

Our sales force has a mixture of team and individual incentives. We create marketing "events" for clients that emphasize the "glamour" of television, and differentiate us from competing media. We try to understand our clients' business and how we can help them achieve their marketing objectives.

\section{Acquiring appropriate international programmes}

I have previously argued the benefits of monopoly purchasing power in commercial programme acquisition. Fiji TV has also been fortunate to be able to "piggyback" on the programme purchasing arrangements of Television New Zealand (TVNZ), one of the larger purchasers of international English language programming. TVNZ has established a small unit called Pacific Service, which acquires, dubs and re-distributes programming on behalf of a number of small Pacific nations. Fiji TV directs TVNZ as to which programmes to acquire on Fiji TV's behalf. As a middleman, TVNZ takes a margin, but the overall 44 PACIFIC JOURNALISM REVIEW 5:1 1999 
efficiencies gained are such that the cost of delivered programmes is considerably less than if we had to manage the purchasing and programme traffic function directly.

As a cost-conscious operator in a small developing market, we also take advantage of whatever free programming is available, either from unencrypted satellite feeds or from various donor agencies. This tends to be suitable for noncommercial off-peak programming, and can provide a worthwhile contribution to information programming. Fiji 1 has a daytime slot called eTV (educational television) based primarily on this material.

\section{Local production}

Local production is crucial to local relevance, quality of the schedule and commercial success. But the realistically achievable amount of local production is limited by its relatively high cost.

Fiji TV is sized around its transmission activities and its news department. All of Fiji TV's in-house local production comes from spare capacity within this resource "shell". Fiji TV has 55 staff working primarily on Fiji 1, our free to air service, and 20 working on Sky Fiji, our pay service. In-house local production for Fiji 1 includes a live half-hour daily national news bulletin, a weekday children's show, a thrice weekly chat show, a weekly music chart show, a weekly indigenous language chat and magazine show, and outside broadcast coverage of sporting events, civic occasions and major entertainment events.

Other local production consists of a magazine programme from a Government video production unit, and "social development programmes" produced by local independent production house and funded by development agencies.

\section{Programming}

The Fiji 1 programming strategy is a fairly standard commercial television model in prime time, with non-commercial programmes in late peak or off-peak. Promos are extremely important in building ratings for commercial programmes but are also used to guide viewers to quality non-commercial programmes in off-peak slots.

The first language of our audience is Fijian or Hindi, and English is frequently the third language. Classic British comedy has appeal to the audience, particularly broad physical comedy such as $\mathrm{Mr}$ Bean. Contemporary UK comedy or drama does not rate well, probably due to difficulty with regional accents or "wordy" scripts, a tendency to dense plot-lines in drama, and a focus 


\section{PETER WILSON}

on class and UK social mores in comedy, which do not resonate with the Fiji audience. The audience tends to find US drama and comedy more accessible. We do however aim to meet the minority interest in quality British drama through a "best of British" night on the pay service. Another impediment to British programmes is the very short run of most series, which means that a series is over before the Fiji audience discovers it. However British variety and light entertainment shows such as Barrymore and Stars In Their Eyes work well in Fiji.

\section{Relations with Government}

Fiji TV encounters ongoing strain in its relationship with Government, some of which is due to the inherent contradictions between a commercial television operation and the traditional model of public service broadcasting in a developing nation.

The Government of Fiji opted for a commercial television service, primarily for fiscal reasons and a partially embraced philosophy of reduced direct Government involvement in the economy. Fiji TV has behaved in the fashion of most commercial broadcasters: it has sought popular programming, it has built a respected independent news bulletin, it has produced an affordable level of local programmes, and it has programmed a commercial schedule.

However, the expectations of some politicians and bureaucrats appear to be:

$\square$ that the television news bulletin should reflect Government public relations,

$\square$ that programming should be primarily "worthy", based on objectives of national development and cultural preservation,

$\square$ that programming should be exclusively "family" oriented.

$\square$ that the schedule should predominantly consist of local production, preferably of traditional culture events.

$\square$ that the company should behave in a non-commercial manner for reasons of social equity.

While a commercial model has been adopted for television in Fiji, some politicians and bureaucrats appear to prefer a Government-controlled public broadcasting model, without having to pay for it. This is not possible. If Fiji TV conformed to these expectations it would go broke. This inherent contradiction results in ongoing tension between Fiji TV and elements of Government. 


\section{Conclusions}

Fiji TV believes that it is possible to deliver quality programming within a commercial framework in a developing country. The first necessity is to achieve commercial viability. A balanced schedule should achieve attractive ratings yet provide diversity. It is desirable to achieve as much other local production as financially sensible. Audience research is necessary to convince advertisers that the higher cost of television advertising is actually cost-effective. Operating costs must be rigorously controlled.

Ratings success should not drive out quality. Accessible information programming or demanding drama can have a place in prime time. Minority appeal, non-commercial programming can have a place in shoulder or off-peak, provided competitive pressures are not too intense. At Fiji TV we are optimistic of delivering quality programming to all significant audience segments through a successful commercial television operation.

$\square$ Peter Wilson is Chief Executive of Fiji Television Ltd. He gave this address at the 1998 Commonwealth Broadcasting Association conference in Gibraltar on 25 May 1998 under the original title, "The Unlevel Playing Field: The Struggle for Commercially Funded Quality Broadcasting."

Email: pwilson@ @ijitv.com.fj 